\title{
3D non-linear FE analysis of a full scale test to failure of a RC Railway Bridge strengthened with carbon fibre bars
}

\author{
Arto Puurula, Ola Enochsson, Gabriel Sas, Thomas Blanksvärd, Ulf Ohlsson, Lars Bernspång, \\ Björn Täljsten, Lennart Elfgren \\ Division of Structural Engineering, Luleå University of Technology, SE-971 87 Luleå, Sweden \\ Contact: arto.puurula@savonia.fi
}

\section{Abstract}

At a full scale loading test to failure a 50 year old concrete railway trough bridge in Örnsköldsvik, in northern Sweden was tested to failure. The test was a part of the European Research Project "Sustainable Bridges" regarding assessment and strengthening of existing bridges. In the project new calculation methods were developed to capture the behaviour of the bridge during increasing load. The bridge was strengthened in bending with rods of Carbon Fiber Reinforced Polymer (CFRP) before the loading test. Failure was reached for an applied load of $11.7 \mathrm{MN}$ by pulling a steel beam placed in the middle of one of the two spans downwards. The achieved failure was a combination of bond, shear, torsion and bending. The developed model, a 3D -non-linear finite element (FE) model with discrete reinforcement, gave accurate accounts of the response of the bridge. The FE calculations show the effect of the strengthening with CFRP and even the effect of the epoxy when using the Near Surface Mounted Reinforcement (NSMR) strengthening method.

Key words: Bridge, Strengthening, Full scale test, Failure Analysis, Bond, Shear, Near Surface Mounted reinforcement (NSMR), Carbon Fibre Reinforced Polymer CFRP), Ultimate load carrying capacity, 3D Non-linear finite element analysis.

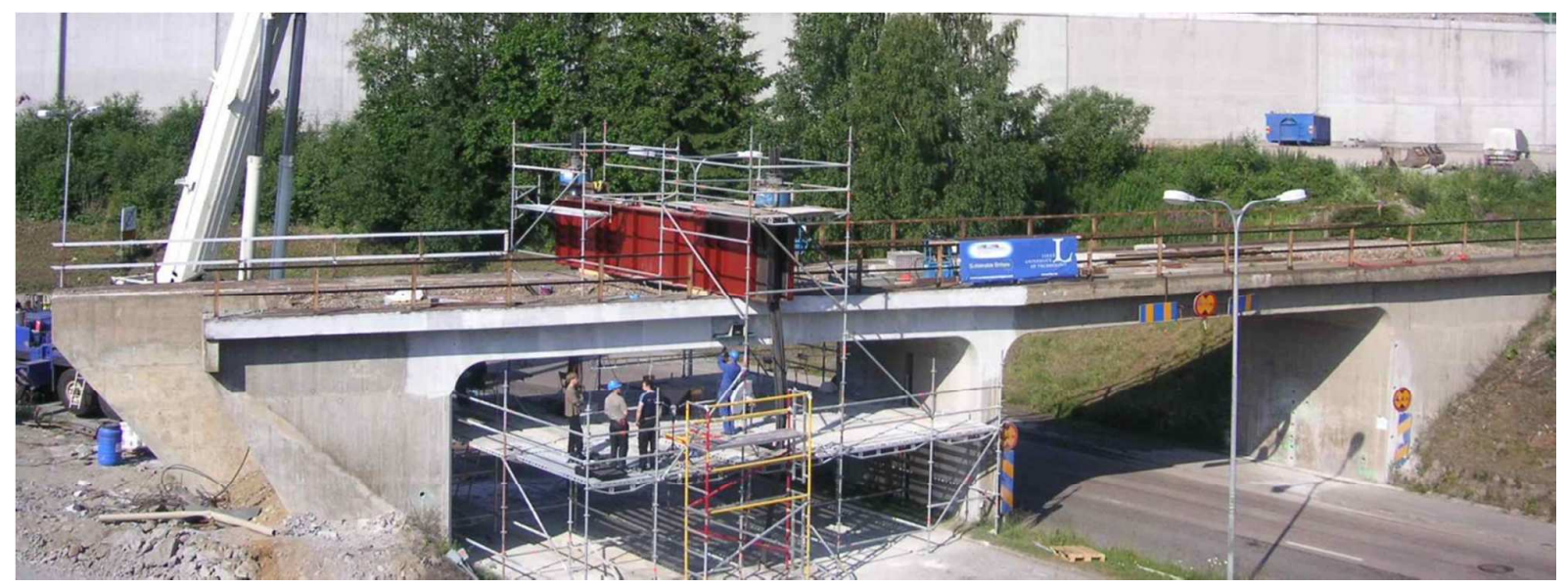

Figure 1. View of bridge in Örnsköldsvik in northern Sweden prior to testing. 


\section{Introduction}

One way to achieve more efficient use of traffic lines is to strengthen the existing railway bridges in order to allow heavier trains to pass the bridges. Another way is to utilize the difference between code calculations and closer estimate of the load carrying capacity of the bridges using advanced computer calculations. The aim of this paper is a combination of these options. The only way to verify computer calculations is to compare calculation results with the measured behavior of a bridge during testing.

The bridge was a reinforced concrete railway trough bridge with two spans, $12 \mathrm{~m}$ each, Figure 1. The bridge was designed to carry a single railway line. The bridge was designed and built in 1955 and was taken out of service in 2005 because of the building of a new high-speed railway, the Bothnia line. Before demolition, the bridge was loaded to failure to test its ultimate load-carrying capacity as part of the European research project Sustainable Bridges, [9]. Original drawings from 1954/55 are reproduced and the testing of the bridge is described in the test report [11].

\section{Description of the $\mathrm{RC}$ trough bridge}

The cross section of the bridge with steel reinforcement and the FPR strengthening is shown in Figure 2.

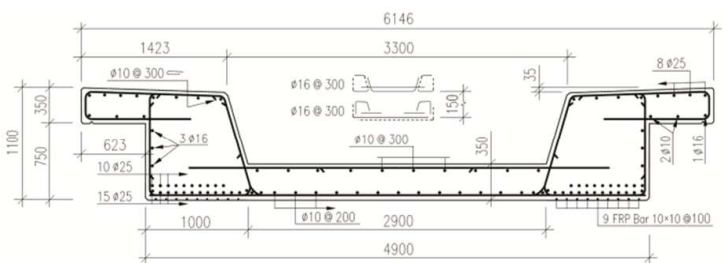

Figure 2. Cross section showing the principal dimensions of the bridge and reinforcement details together with the location of the nearsurface mounted reinforcement (NSMR) with FRP Bar M10C on $100 \mathrm{~mm}$ centers.

In Table 1 a summary of the material parameters used in the analysis of the bridge, is presented. Initial properties are given first based on the original drawings followed by updated properties based on the tested mean values.

Table 1. Summary of Material Properties

\begin{tabular}{|c|c|c|c|c|c|c|c|c|c|c|}
\hline \multirow[b]{3}{*}{ Material and its properties } & \multicolumn{4}{|c|}{ Concrete } & \multicolumn{3}{|c|}{ Steel } & \multicolumn{3}{|c|}{ CFRP } \\
\hline & $\mathbf{f}_{\mathrm{c}}$ & $f_{t}$ & $\mathrm{E}_{\mathrm{c}}$ & $\mathrm{G}_{\mathrm{F}}$ & $\mathbf{f}_{\mathrm{sy}}=\mathrm{R}_{\mathrm{eh}}$ & $\mathbf{f}_{\mathrm{su}}=\mathrm{R}_{\mathrm{m}}$ & $E_{s}$ & $\mathbf{f}_{\mathrm{f}}$ & $E_{f}$ & $\varepsilon_{\mathrm{uf}}$ \\
\hline & $\mathrm{MPa}$ & $\mathrm{MPa}$ & $\mathrm{GPa}$ & $\mathrm{N}=\mathrm{m}$ & $\mathrm{MPa}$ & $\mathrm{MPa}$ & $\mathrm{GPa}$ & $\mathrm{MPa}$ & $\mathrm{GPa}$ & $\%$ \\
\hline $\begin{array}{l}\text { Initial characteristic properties } \\
\text { based on drawings }\end{array}$ & 31 & 1.8 & 32 & - & $\varnothing 16: 410$ & $\varnothing 16: 500$ & 200 & 2,500 & 260 & $\approx 0.8$ \\
\hline $\begin{array}{l}\text { Mean properties based on tests } \\
\text { (standard deviations are given } \\
\text { in parenthesis) }\end{array}$ & $68.5(8)$ & $\begin{array}{l}2.2(0.5) \\
\text { uniaxial }\end{array}$ & $\begin{array}{l}25.4(1.7) \\
\text { tension }\end{array}$ & $154(82)$ & $\begin{array}{l}\varnothing 16: 441(12) \\
\varnothing 25: 411(8.2)\end{array}$ & $\begin{array}{l}\varnothing 16: 738(2.4) \\
\varnothing 25: 706(22.6)\end{array}$ & $\begin{array}{l}\varnothing 16: 192.1 \\
\varnothing 25: 198.3(31.5)\end{array}$ & - & - & - \\
\hline
\end{tabular}

Note: For the concrete: $\mathbf{f}_{c}=$ compressive strength; $\mathbf{f}_{t}=$ tensile strength; $E_{c}=$ modulus of elasticity; and $G_{F}=$ fracture energy. For the steel: $\mathbf{f}_{\mathrm{sy}}=R_{\mathrm{eh}}$ is the yield stress; $\mathbf{f}_{\mathrm{su}}=R_{\mathrm{m}}$ is the ultimate stress; and $\mathrm{E}_{\mathrm{s}}=$ modulus of elasticity. For the CFRP: $\mathbf{f}_{\mathbf{f}}=$ tensile strength; $\mathrm{E}_{\mathbf{f}}=$ modulus of elasticity; and $\varepsilon_{\mathrm{uf}}=$ failure strain.

\section{Strengthening of the bridge with carbon fibre, CFRP bar}

The edge beams of the bridge were strengthened before the test with $9+9=18$ StoFRP Bar M10C with a length of $10 \mathrm{~m}$ and a rectangular cross section of $10 \times 10 \mathrm{~mm}$, Figure 2 . They were installed on $100 \mathrm{~mm}$ centers using the nearsurface mounted reinforcement technique
(NSMR) in presawn grooves, $15 \times 15 \mathrm{~mm}$ filled with epoxy in the slab in the soffit of the bridge, see Figures 3 . The aim of the strengthening was twofold: (1) to get and investigate shear failure of the edge beams, rather than bending failure for which good calibrated models are already available; (2) to test strengthening with NSMR reinforcement of CFRP bars. 
The strengthening of the bridge was successful; the FRP bars both increased the stiffness and the bending moment capacity of the bridge. The strengthening procedure is described in [10]. The strengthening method can be studied in detail in [12].

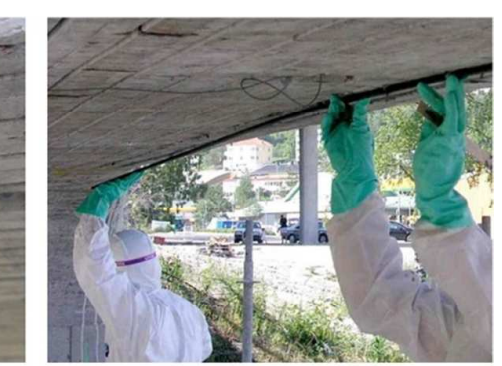

(c)

(a)

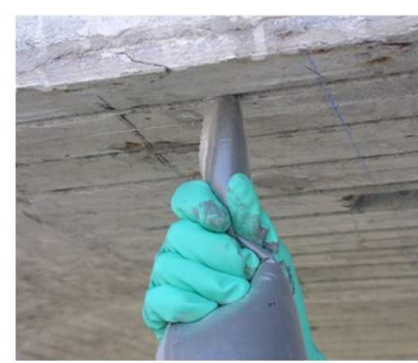

(b)

Figure 3. Installation of the NSMR showing (a) sawing of grooves; (b) filling grooves with epoxy adhesive; (c) grooves following insertion of the CFRP reinforcement.

\section{Loading to failure}

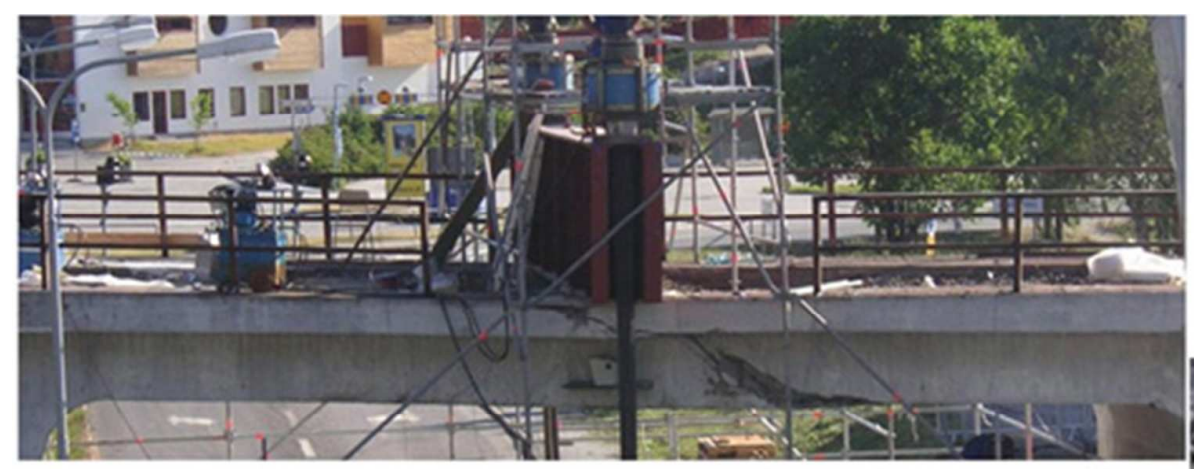

(a)

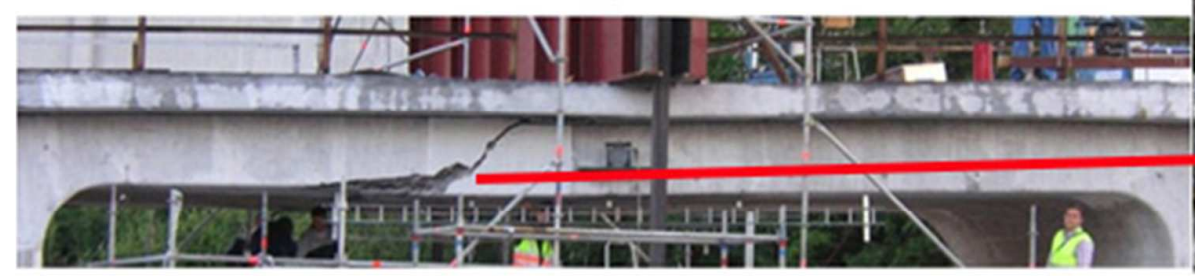

(b)

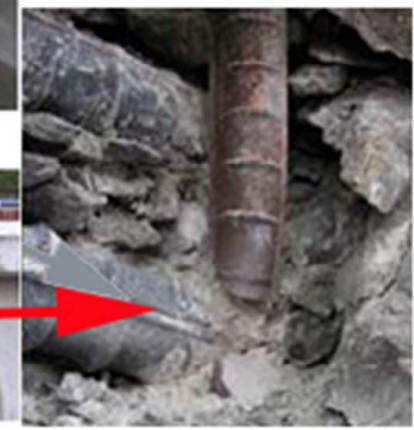

c)

Figure 4. Failure cracks with ruptured stirrups in the beams after the maximum load of $11.7 \mathrm{MN}$ in the span close to the South abutment: (a) West edge beam; (b) East edge beam; (c) ruptured stirrup.

The final failure started in the East edge beam, Figure $4 \mathrm{~b}$. The ruptured stirrup on the East side of the bridge is shown in Figure 4c. The wide shear crack indicates that the stirrups were ruptured all along the crack. The bridge behaviour during the increasing test load is described based on measured deformations and strains and also on descriptions of the failure process and comparisons with code values. These have been given in the Sustainable Bridges project deliverable [11], doctoral theses [4], [7], scientific articles of the Övik bridge [5] and assessment of the train load capacity of the Övik bridge [6] and in papers presented at the XXI Nordic Concrete Research Symposium [3], [8]. 


\section{3D non-linear Finite Element model}

The Övik Bridge was modeled using Abaqus based software Brigade [1].

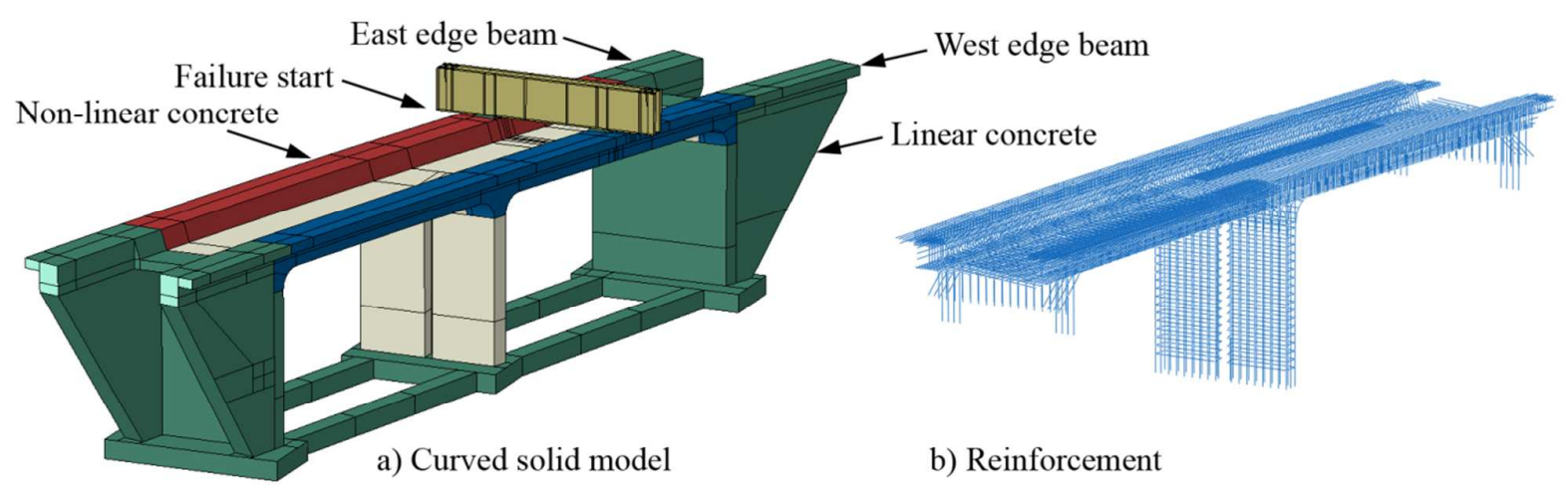

Figure 5. a) Model of bridge with concrete modelled as non-linear in the bridge slab, edge beams and mid columns, which deflect most and crack and linear in the lower parts. b) non-linear discrete steel reinforcement is embedded in the concrete model of the bridge with perfect bond to the concrete. The carbon fibre, CFRP bars are modelled first with perfect bond to the concrete and then embedded in epoxy, in order to find out the effect of epoxy.

This FEM model is sufficiently detailed to include an interface between the epoxy and the concrete to allow studying the bond failure.

\section{Results}

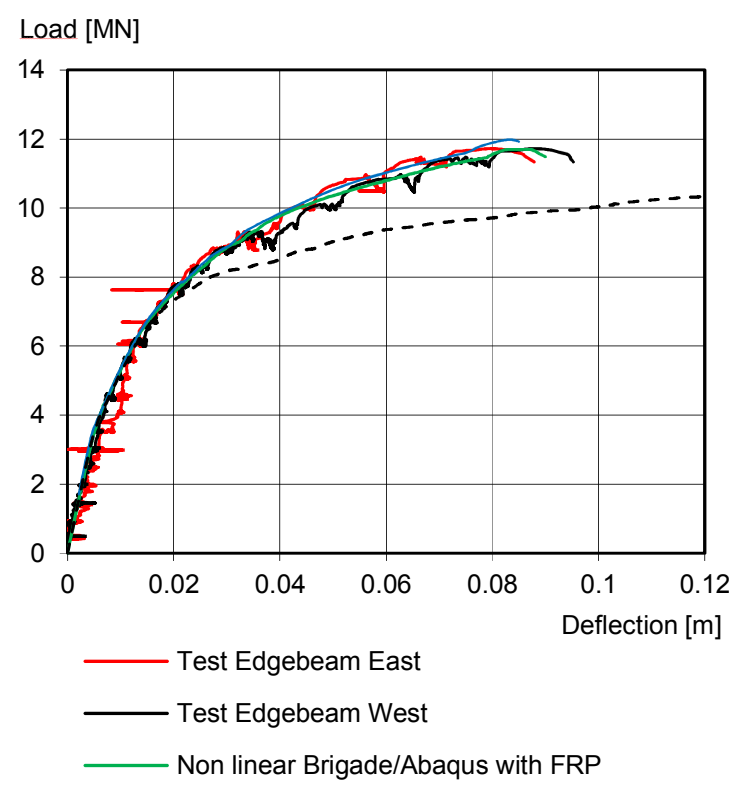

Figure 6. Load-deflection curves for different models.
Comparisons between test measurements, the model with FRP bars embedded in epoxy, the model without epoxy and the model without strengthening are presented in the following figures. The bridge exhibits ductile behaviour with a large deflection of the order of $0.1 \mathrm{~m}$ before failure. The ultimate load capacity was reached at an applied midspan load of 11.7 MN. The load carrying capacity increases with about $20 \%$ after strengthening

The final failure including the bond failure between epoxy and concrete is described and the following diagrams are explained in more detail in [5] and [6]. The bond failure accelerated the loss of stiffness. According to the variable angle truss shear model used in Eurocode 2 there is a connection between the tensile force in the bending reinforcement and the shear force taken by the stirrups. When the tensile force decreases, the stirrups take a bigger part of the shear force and the stress in the stirrups increases accordingly. 
In the West edge beam, see Figure 7, the model including epoxy is in closer agreement with measured strain values compared with the model where the FRP bars have perfect bond to the concrete.

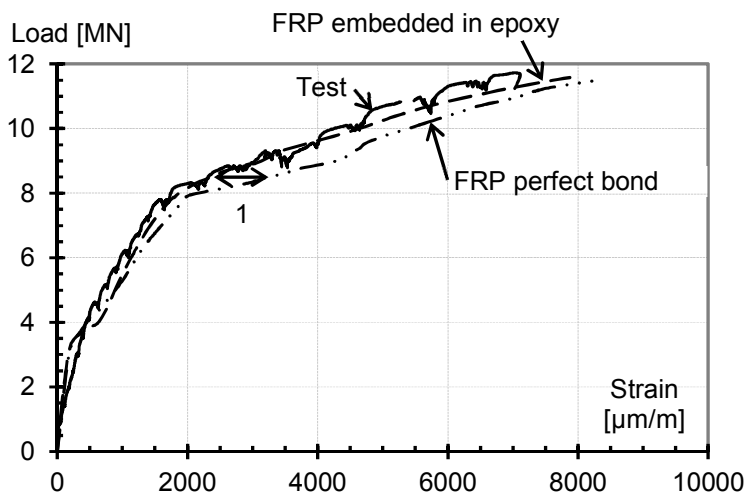

Figure 7. Elastic strains in carbon fibre reinforcement, FRP, in the West edge beam in the FE calculation node closest to the measurement point.

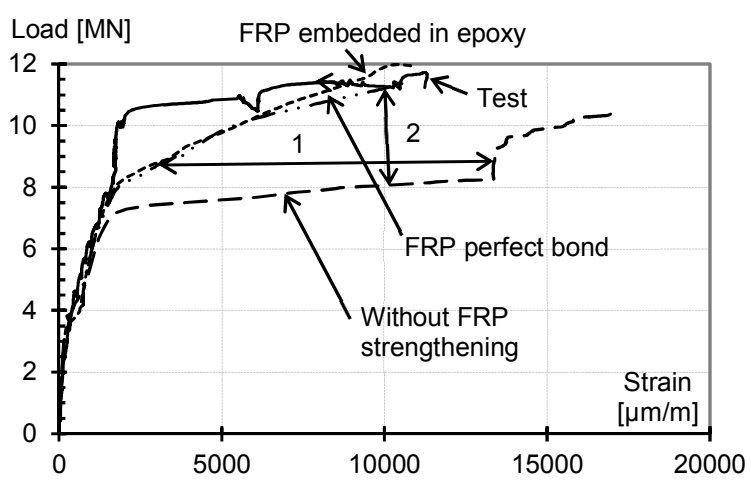

Figure 8. Strains in tensile steel $\varnothing 25$ reinforcement in the East edge beam in a node closest to the measurement point.

The FRP reinforcement can to some extent move inside the epoxy. Therefore the FRP strains are smaller in the model including epoxy than in the model not including epoxy where there is a perfect bond between the FRP and the concrete. This can especially be seen in Figure 7 after load level of $8 \mathrm{MN}$ when the steel reinforcement in Figure 8 has started to yield and the FRP reinforcement begins to take more load. The effect of epoxy, difference 1 , in Figure 7 becomes as big as $25 \%$ after the load level of $8 \mathrm{MN}$. The strains in the steel reinforcement follow the strains in the FRP bars. That is why the steel strains also become smaller in the model with FRP bars embedded in epoxy in Figures 8 at high load levels.

The FRP strengthening has an increasingly stiffening effect on the bridge, the difference 1 in Figure 8 . The strengthening effect can clearly be seen as the difference 2 .

The first visible bond failure in the interface between the epoxy and the concrete occurred in the outermost epoxy groove in the West edge beam. The bond stresses S13 according to Brigade calculation are shown in the diagram in Figure 10a). The direction and location of S13 is explained in Figure 10b). There are clear peak values with a maximum average value of $\mathrm{S} 13=-$ $5.342 \mathrm{MPa}$ in the middle of the epoxy groove.

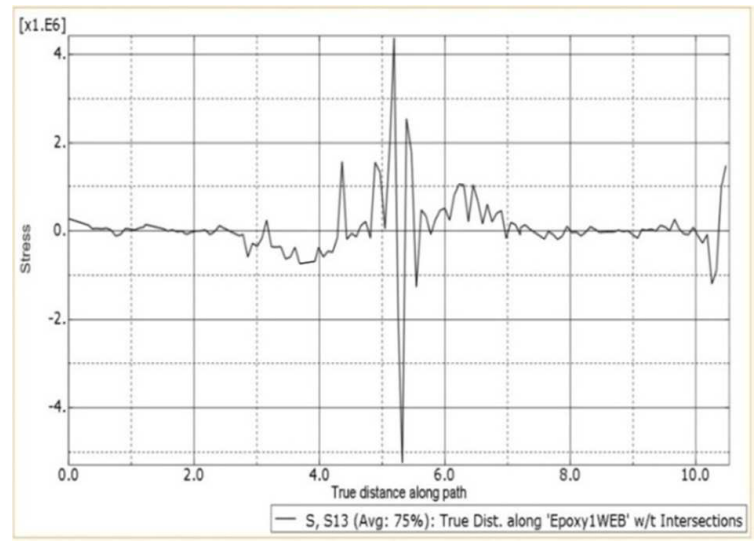

Figure 9. Bond stresses $\mathrm{S} 13=\mathrm{S} 31$, in the interface between epoxy and concrete according to Brigade calculation along the outermost epoxy groove in the West edge beam. The maximum averaged value is $\mathrm{S} 13=-5.343 \mathrm{MPa}$. The location of the groove is shown in Figure 10b).

The not averaged value of S13, which occurs in the same place as the peak value in Figure 9, is much higher, see Figure 10b) where S13 $=-11.37$ $\mathrm{MPa}$. This high bond stress value clearly indicates the risk for bond failure and it occurs in exact the same place as where the bond failure occurred during the loading test. This is higher than the bond strength of $9.0 \mathrm{MPa}$ for this type of bar in [2]. 
After debonding, the FRP reinforcement acted as a tensile rod outside the concrete. The bond failure lowered the available tensile force at the bottom of the bridge and increased the inclination of the concrete compression struts which produced higher stresses in the stirrups, as fewer stirrups had to carry the load. The formed mechanism led to the finale shear failure of the bridge.

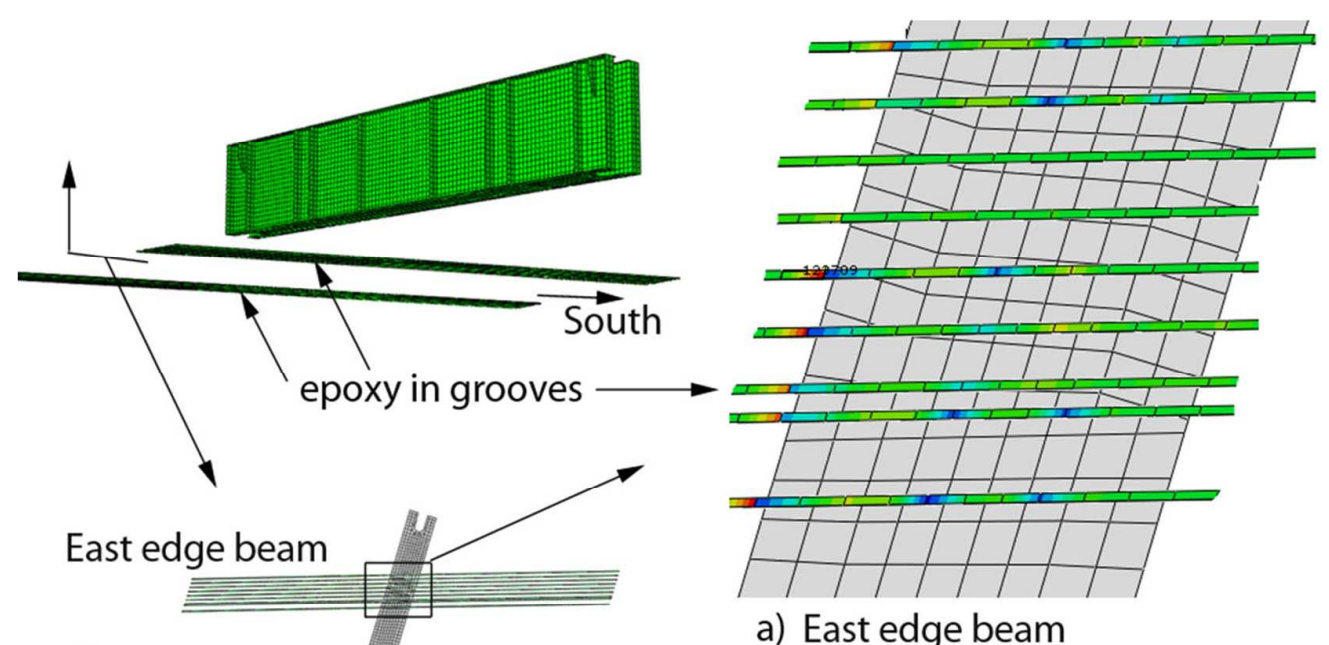

a) East edge beam

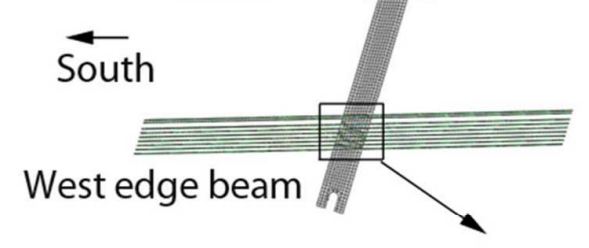

b) West edge beam

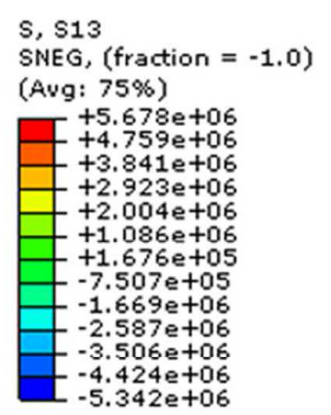

S13 max: $-5.343 \mathrm{MPa}$

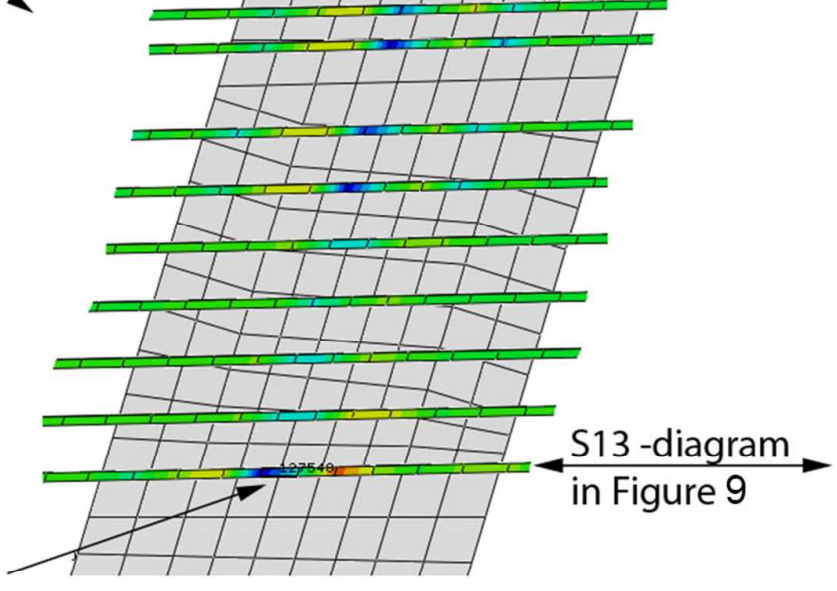
(averaged)

S13 max: $-11.37 \mathrm{MPa}$ (not averaged)

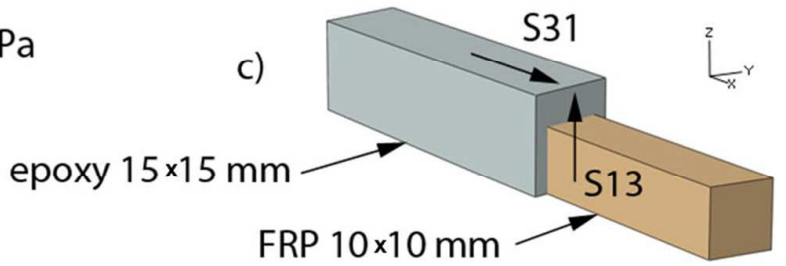


Figure 10. Bond stresses, $\mathrm{S} 13=\mathrm{S} 31$, in the interface between epoxy and concrete.

(a) East and (b) West edge beam from below.

(c) Detail of FRP and epoxy in a groove in the bottom of the concrete beam

\section{Summary and conclusions}

The aim of this paper has been to describe how the load carrying capacity has been assessed for a concrete railway bridge which was loaded to failure in a full scale test in Örnsköldsvik, Sweden. The bridge was strengthened with carbon fibre, FRP bars before testing.

In the final test, a failure was reached for an applied mid span load of $11.7 \mathrm{MN}$ by pulling a steel beam placed in the middle of one of the two spans downwards. At the failure load the longitudinal steel reinforcement and the stirrups were yielding. The additional load was carried by the FRP bars which increased the bond stresses between the epoxy adhesive for the FRP bars and the surrounding concrete. The bond failure which followed was caused by combined action of shear, torsion and bending. After the bond failure a mechanism was formed. The bond failure caused decreased forces in the tensile reinforcement and a redistribution of internal forces to the stirrups. This together with increased inclination of the concrete compression struts with fewer stirrups crossing the formed shear crack to carry the shear force, increased stresses in the stirrups up to the ultimate stress. From the time of the bond failure up to the final failure, the process was driven by the formed mechanism. The torsion relaxed in some amount and a wide shear-bending crack through the entire bridge was formed.

It was shown that the behaviour of the bridge during increasing load can be closely predicted with the developed 3D non-linear FE model up to the load when the bond failure occurred. Steel reinforcement was in all models modelled as discrete bars with perfect bond between the steel bars and concrete. FRP carbon fibre reinforcement bars were modelled first with perfect bond and then embedded in epoxy filled grooves.

The computer model could not reproduce the mechanism formed after the bond failure. It was not possible to achieve failure stresses in stirrups with the numerical model used. The calculated stresses in stirrups remained at yield level at the failure load, which led to alternative explanations to the final failure. The drop of force in FRP reinforcement due the debonding of FRP and the thereby following force transfer, according to the variable angle truss method for shear used in e.g. Eurocode 2 (2004), from tensile, bending reinforcement to stirrups explained the behavior of the bridge from the bond failure up to the failure load.

The modelling of the grooves, where the FRP bars were mounted embedded in epoxy, offered an interface between the epoxy and the concrete in the computer model. The calculated shear stresses in this interface show a peak value exactly in the same place where the bond failure started. The bond strength between epoxy and concrete was exceeded indicating the event which started the mechanism which led to the final failure.

It is evident that the response of the bridge can be closely followed and easily observed at any time during the increasing load when a nonlinear one-to-one full scale model with discrete reinforcement is used. A 3D model behaves in an integrated way including twists and deflections in all directions.

The paper shows that the developed 3D nonlinear FE model can be used as a reference tool to assess the load carrying capacity and the structural safety of reinforce concrete bridges, being a reliable alternative to the currently used calculation methods.

The method developed described in this paper has been used to get a close estimation of the load carrying capacity for a train load.

\section{ACKNOWLEDGEMENTS}


The authors gratefully acknowledge support and contributions from: the European Union 6th Framewok Program; Banverket, Sweden; Luleå University of Technology (LTU), Sweden; Savonia University of Applied Sciences, Finland; Finnish Rail Administration, Finland, Finnish Road Cervenka Consulting, Czech Republic; COWI A/S, Denmark; Denmark Technical University (DTU), Denmark; Nordisk Spännarmering, Sweden; University of Oulu, Finland, Skanska Sverige AB,

\section{References}

[1] Brigade. (2011). Brigade software, (http://www.scanscot.com/products/ove rview/)(Jun. 7, 2014).

[2] Nordin, H, and Täljsten, B. (2003). "Concrete beams strengthened with CFRP. a study of anchor lengths." Proc. 10th Conf. on Structural Faults and Repair, Engineering Technical Press, Edinburgh, Scotland, 135.

[3] Puurula, A., Enochsson, O., Thun, H., Nordin, H., Täljsten, B., Elfgren, L., Olofsson, J. (2008). Full-scale test to failure of a strengthened reinforced concrete bridge: calibration of assessment models for load-bearing capacities of existing bridges. Nordic Concrete Research, (2), 131-142

[4] Puurula, A. (2012). "Load-carrying capacity of a strengthened reinforced concrete bridge. Non-linear finite element modeling of a test to failure. Assessment of train load capacity of a two span railway trough bridge in Örnsköldsvik strengthened with bars of carbon fibre reinforced pol- ymers (CFRP)." Doctoral thesis, Division of Structural Engineering, Luleå Univ. of Technology, Luleå, Sweden, 328.

[5] Puurula, A., Enochsson, O., Sas, G., Blanksvärd, T., Ohlsson, U., Bernspång, L., Elfgren, L. (2014). Loading to failure and 3D nonlinear FE modelling of a strengthened RC bridge.Structure \& Infrastructure Engineering, 10(12), 16061619. $10.1080 / 15732479.2013 .836546$
Administration, Finland, The Federal Institute for Materials Research and Testing (BAM), Germany; Botniabanan, Sweden; City University, England;

Sweden; STO Skandinavia AB, Sweden; Örnsköldsviks kommun, Sweden; and University of Minho (UMINHO), Portugal.

[6] Puurula, A., Enoksson, O., Sas, G., Blanksvärd, T., Ohlsson, U., Bernspång, L., Elfgren, L. (2015). Assessment of the Strengthening of an RC Railway Bridge with CFRP utilizing a Full-Scale Failure Test and Finite-Element Analysis. Journal of Structural Engineering, 141(1 (Special Issue)), D4014008-1 to D4014008-11. [D4014008 ]. 10.1061/(ASCE)ST.1943541X.0001116

[7] Sas, G. (2011). "FRP shear strengthening of reinforced concrete beams." Doctoral thesis, Luleå Univ. of Technology, Luleå, Sweden.

[8] Sas, G., Blanksvärd, T., Enochsson, O., Täljsten, B., Puurula, A., and Elfgren, L. (2011). "Flexural-shear failure of a full scale tested RC bridge strengthened with NSM CFRP: Shear capacity analysis." Nordic Concr. Res., 2/2011(44), 189-206.

[9] Sustainable Bridges (SB). (2008). "Sustainable bridges-Assessment for future traffic demands and longer lives." (www.sustainablebridges.net) (Jun. 7, 2014).

[10]Sustainable Bridges (SB)-6.3. (2007). "Field Tests. Örnsköldsvik bridge- Full scale testing; Vitmossen-Strengthening of the subsoil; Frövi bridge-

Strengthening and monitoring." Deliverable D6.3. Sustainable Bridges-a project within EU FP6, B. Täljsten and A. Carolin, eds., Luleå Univ. of Technology, Luleå, Sweden.

[11]Sustainable Bridges (SB)-7.3. (2008). "Field Test of a concrete bridge in Örnsköldsvik, Sweden." Deliverable D 7.3, sustainable bridges, L. Elfgren, $\mathrm{O}$. 


\section{Page 9 of 9}

Enochsson, and $\mathrm{H}$. Thun, eds., Luleå Univ. of Technol- ogy, Luleå, Sweden.

[12]Täljsten, B., Blanksvärd, T., and Sas, G. (2011). Handbok för dimensioner- ing $i$ samband med förstärkning av betongkonstruktioner med pålim- made fiberkompositer [Design Guideline for FRP Strengthening of Existing Concrete Structures], Division of Structural Engineering, Luleå Univ. of Technology, Luleå, Sweden, 184 (in Swedish). 